\title{
A field and numerical study of the evolution of sea-ice thickness in the Ross Sea, Antarctica, 1998-99
}

\author{
Tina TIN,${ }^{1}$ Ralph TIMMERMANN ${ }^{2}$ Martin O. JEFFRIES ${ }^{1}$ \\ ${ }^{1}$ Geophysical Institute, University of Alaska, 903 Koyukuk Drive, Fairbanks, Alaska 99775-7320, U.S.A. \\ E-mail:tina.tin@gi.alaska.edu \\ ${ }^{2}$ Institut d’Astronomie et de Géophysique G. Lemaître, Université Catholique de Louvain, B-1348 Louvain-la-Neuve, Belgium
}

\begin{abstract}
During two cruises in 1998 and 1999, we examined drift and ridging characteristics of sea ice in the Ross Sea, Antarctica. Mean ice thickness in the western Ross Sea in autumn was $0.5 \mathrm{~m}$, while higher level-ice thicknesses, greater areal coverages of ridges and higher sails were found in the central and eastern Ross Sea in summer. Near the continent, ice drifted westward near the coast and turned eastward further north. We use a regional sea-ice--mixed-layer-pycnocline model to initiate backward trajectories at the time and location of field observations and examine the dynamic and thermodynamic processes that determine ice thickness along these trajectories. Model results agree with previously published field data to indicate that thermodynamic and dynamic thickening and snow-ice formation each contribute significantly to the ice mass of the summer ice field in the central and eastern Ross Sea. For first-year ice in the western Ross Sea, model results and field data both indicate that thermodynamic thickening is the dominant process that determines ice thickness, with dynamic thickening also contributing $20 \%$ to the net ice-thickening rate. However, model results fail to reproduce the prevalence of snowice formation that was seen in field data.
\end{abstract}

\section{INTRODUGTION}

Due to the vastness and remoteness of the Ross Sea ice cover, it is difficult to examine its time-varying characteristics in detail and over a broad scale simultaneously. Satellite remote-sensing data allow changes in ice concentration to be examined over a large area and over long periods (Zwally and others, 1985). Sampling of ice floes from icebreakers can provide snapshots of ice characteristics localized in time and space (Lange and Eicken, 1991). While the processes involved in the formation of the sampled ice can be inferred from the crystal structure of the ice, at what

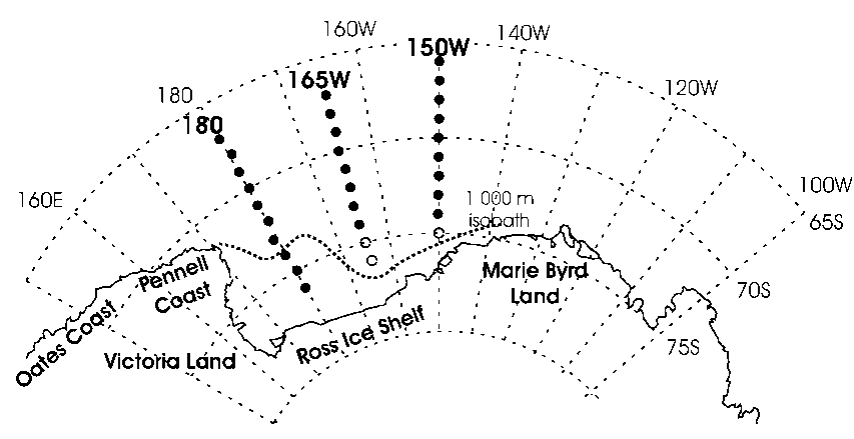

Fig. 1. Circles indicate locations of summary ASPeCt observations from cruises NBP 98-3 and NBP 99-1 in May 1998 and Fanuary 1999 respectively. Each summary observation is derived from averaging observations within the same $1^{\circ}$ latitude bin. Closed circles $(\bullet)$ represent locations of summary observations which are used to initiate backward trajectories in our study. The dotted curve represents the approximate location of the $1000 \mathrm{~m}$ isobath which is considered as the edge of the continental shelf. location and time those processes occurred cannot easily be determined. Numerical models provide well-controlled laboratories to examine the cumulative processes involved in the formation of observed phenomena (Fichefet and Goosse, 1999). However, the lack of compatible field data to validate numerical output often limits the interpretation of simulation results.

In this study, we combine the ground truth of detailed field observations with the power of a numerical model to gain insight into the processes that determined the thickness of the Ross Sea ice pack observed on two icebreaker cruises. Our observations were made along $180^{\circ}$ longitude in May 1998 and along $165^{\circ} \mathrm{W}$ and $150^{\circ} \mathrm{W}$ in January 1999 (Fig. 1), aboard the R/V Nathaniel B. Palmer during cruises NBP 983 and NBP 99-1. These were semi-quantitative shipboard observations recorded following the protocol developed by the Antarctic Sea Ice Processes and Climate (ASPeCt) program and are available from the ASPeCt data archive. ASPeCt is part of the Scientific Committee on Antarctic Research (SCAR) Global Change and the Antarctic program (GLOCHANT), and one of its goals is to define the broad-scale, time-varying characteristics of Antarctic sea ice. To this end, it has been promoting and archiving summer, autumn, winter and spring measurements of key characteristics of the Antarctic sea-ice cover along transects perpendicular to the Antarctic coast and spaced at intervals of about $15-30^{\circ}$ of longitude. The numerical model we employ is the regional sea-ice--mixed-layer-pycnocline model used by Fischer and Lemke (1994), Harder and Lemke (1994) and Timmermann and others (1999). The model is used to simulate the observed ice pack and to derive backward trajectories of the ice observed during NBP 98-3 and NBP 99-1. Backward trajectories are initiated at the location 
and time of observation, and are traced backward in time. We then focus on the dynamic and thermodynamic processes which determine ice thickness along these trajectories and examine the relative importance of different processes and their variations in time and space.

\section{SHIP OBSERVATIONS METHODOLOGY}

According to the ASPeCt protocol, a standard set of observations is made hourly by an observer on the ship's bridge. These include the ship's position and total ice concentration, and an estimate of the areal coverage, thickness, floe size, topography (i.e. areal coverage and mean height of ridge sails), and snow cover of the three thickest ice categories within a radius of approximately $1 \mathrm{~km}$ of the ship (Worby and Allison, 1999). An equivalent thickness is calculated from each set of observations. Equivalent thickness is the thickness of a flat slab of ice which has the same volume as contained in all the ridges and level ice within the radius of observation. It is estimated from the areal coverage and mean height of sails, and the surrounding level-ice thickness using

$$
\begin{aligned}
z_{\mathrm{r}} & =0.5 R S+z_{\mathrm{u}}+p_{\mathrm{R}} r^{*}(0.5 R S)+p_{\mathrm{L}}(1-R) K_{\mathrm{L}} \\
p_{\mathrm{L}} & =0 \text { for } R \leq 0.05
\end{aligned}
$$

(Tin and others, 2003), based on a modified version of the original ASPeCt formula published by Worby and Allison (1999). The equivalent thickness, $z_{\mathrm{r}}$, is calculated based on the assumption that the observed ice is made up of level ice with a thickness of $z_{\mathrm{u}}$, triangular ridge sails that have mean heights and areal coverage of $S$ and $R$, and possibly ridge keels which contain $r^{*}$ times as much ice as in the sails (Tin and others, 2003). However, ridge keels are not always associated with a ridge sail (Tin and Jeffries, 2003; Tin and others, 2003). Consequently, we take into account $p_{\mathrm{R}}$, the probability that a ridge sail on the surface is associated with a ridge keel underwater, and $p_{\mathrm{L}}$, the probability that a keel is below a level top surface. The probability that there is a keel underneath a level surface, $p_{\mathrm{L}}$, is assumed to be negligible for areas which are covered by ridge sails that make up $<5 \%$ of the total surface area, i.e. $R \leq 0.05$. Based on data from three cruises, the mean variance of estimates of $z_{\mathrm{r}}$ for an individual ASPeCt observation is estimated to be $18 \%$ (Tin and others, 2003).

In order to obtain a spatial resolution which is close to that of the sea-ice model (see section 4) we averaged the ASPeCt observations recorded during cruises NBP 98-3 and NBP 99-1 over $1^{\circ}$ latitude intervals. The resultant average observations are referred to as summary observations, and their locations are illustrated in Figure 1. Based on the variance of $z_{\mathrm{r}}$ for an individual observation and the number of observations within each $1^{\circ}$ latitude bin, we estimate that the mean variance of estimates of $z_{\mathrm{r}}$ for a summary observation is $3 \%$.

Worby and Wu (1998) have shown that climatological ice-thickness data constructed from ASPeCt observations that have been collected over a long period of time can be used satisfactorily to validate numerical models. Unfortunately, the number of ASPeCt observations is limited in the Ross Sea. Hence, in this study, we can only use our observations to assess ice conditions at a specific time and location.

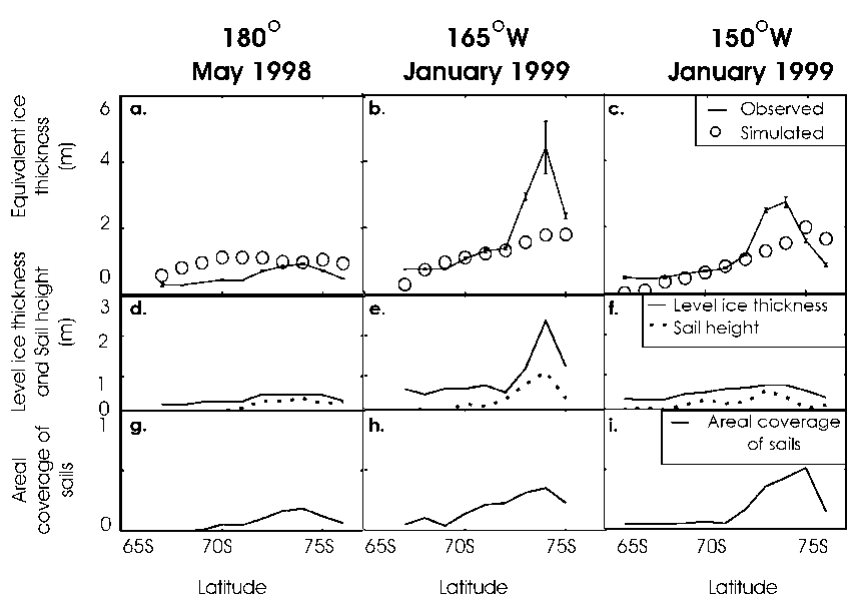

Fig. 2. ( $a-c)$ Plots of equivalent thickness derived from ASPeCt observations (solid line) and ice thickness simulated by the model (o) along $180^{\circ}$ in May 1998 (a), $165^{\circ} \mathrm{W}$ in January 1999 (b) and 150 $\mathrm{W}$ in January 1999 (c). Equivalent thickness is plotted together with its error bars. $(d-f)$ Plots of observed level-ice thickness (solid line) and ridge sail height (dotted line) along $180^{\circ}$ in May 1998 (d), $165^{\circ} \mathrm{W}$ in Fanuary 1999 (e) and 150 W in Fanuary 1999 $(f)$, as recorded in ASPeCt observations. ( $g-i)$ Plots of observed areal coverage of sails along $180^{\circ}$ in May $1998(\mathrm{~g})$, $165^{\circ} \mathrm{W}$ in Fanuary $1999(\mathrm{~h})$ and $150^{\circ} \mathrm{W}$ in Fanuary 1999 (i), as recorded in ASPeCt observations.

\section{ROSS SEA ICE CONDITIONS OBSERVED IN 1998 AND 1999}

\subsection{Ice thickness}

Figure 2 displays ice-thickness values derived from ASPeCt summary observations at the locations indicated by Figure 1. Along $180^{\circ}$ in May 1998 , mean equivalent thickness was $0.5 \mathrm{~m}$. Equivalent thickness reached a maximum at $74^{\circ} \mathrm{S}$ as a result of a high areal coverage of large sails. Equivalent thickness, areal coverage of sails and sail heights all decreased both northward and southward. North of $70^{\circ} \mathrm{S}$, areal coverage of sails and sail heights were small, and the computed equivalent thickness was primarily determined by the observed level-ice thickness.

Along $165^{\circ} \mathrm{W}$ and $150^{\circ} \mathrm{W}$ in January 1999 , equivalent thicknesses averaged at 1.7 and $1.1 \mathrm{~m}$ and reached maximum values of 4.4 and $2.8 \mathrm{~m}$ at $74^{\circ} \mathrm{S}$. Equivalent thicknesses along $165^{\circ} \mathrm{W}$ and $150^{\circ} \mathrm{W}$ in January 1999 were significantly larger than along $180^{\circ}$ in May 1998 , due to a combination of higher level-ice thickness, areal coverage of sails and sail height. Along $165^{\circ} \mathrm{W}$, the maximum in equivalent thickness was accompanied by maxima in level-ice thickness, areal coverage of sails and sail height. Along $150^{\circ} \mathrm{W}$, level-ice thickness was at a maximum at $74^{\circ} \mathrm{S}$, but maxima in sail height and areal coverage of sails were at $73^{\circ} \mathrm{S}$ and $75^{\circ} \mathrm{S}$, respectively.

\subsection{Sea-ice drift}

Figure 3 presents the trajectories of three of the seven buoys deployed during NBP 98-3 and both the buoys deployed during NBP 99-1 (Jeffries and Kozlenko, 2002). The buoys deployed in May 1998 transmitted for an average of 85 days, while the longest data record (Fig. 3a) lasted for 216 days. The buoys initially all traveled northwestward around 


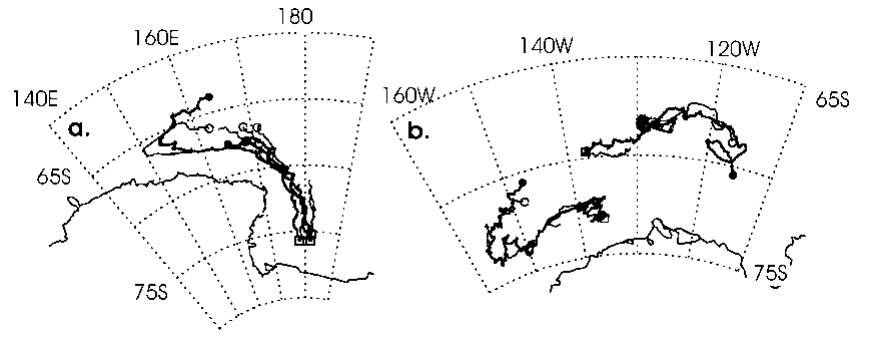

Fig. 3. Observed (heavy lines) and simulated (light lines) drift trajectories of buoys deployed during NBP 98-3 in May 1998 ( a) and NBP 99-1 in Fanuary 1999 (b). $\square$ denote the location at which the buoys were deployed. $\bullet$ denote the end of observed drift trajectories. $\mathrm{O}$ denote the end of simulated drift trajectories. After every 60 days, simulated buoys are restarted at the location of the observed drift trajectory.

Cape Adare, while one buoy continued westward along the Pennell Coast until it joined the Antarctic Circumpolar Current (ACG) and drifted eastward.

The two buoys deployed in January 1999 transmitted for an average of 310 days. They were deployed near $137^{\circ} \mathrm{W}$ and traveled in different directions. The buoy deployed at $70^{\circ} \mathrm{S}$, $138^{\circ} \mathrm{W}$ drifted eastward, while the buoy deployed at $74^{\circ} \mathrm{S}$, $136^{\circ} \mathrm{W}$ initially drifted westward and then turned eastward at $155^{\circ} \mathrm{W}$.

\section{MODEL DESGRIPTION AND GHOIGE OF MODEL PARAMETERS}

\subsection{Model components}

The model used in this study is a dynamic-thermodynamic sea-ice model coupled to a one-dimensional mixed-layerpycnocline model (Lemke and others, 1990). Sea-ice momentum balance is computed using a viscous-plastic rheology (Hibler, 1979). Thermodynamic growth rates are derived from a surface energy balance (Parkinson and Washington, 1979) using the Semtner (1976) zero-layer approach for heat conduction. A prognostic snow layer (Owens and Lemke, 1990) considering the effect of snow/ ice conversion (Leppäranta, 1983; Fischer, 1995) is included. The model has been used in a number of sea-ice studies focused on the Southern Ocean (e.g. Stössel and others, 1990; Fischer and Lemke, 1994; Timmermann and others, 1999).

For our study, the model is run on a circumpolar grid with zonal boundaries at $50^{\circ} \mathrm{S}$ and $82^{\circ} \mathrm{S}$ with an isotropic resolution of $1.5^{\circ}$ zonally and $1.5^{\circ} \cos \phi$ meridionally for the whole model domain. Daily U.S. National Centers for Environmental Prediction (NCEP)/U.S. National Center for Atmospheric Research (NCAR) re-analysis data for $10 \mathrm{~m}$ wind speed, $2 \mathrm{~m}$ air temperature, specific humidity, cloudiness and net precipitation $(P-E)$ are used for atmospheric forcing. An integration for the 9 year period 1985-94 serves as the spin-up. The model is then run for the period 1995-99 for analysis. Surface ocean currents are taken from output of the BRIOS-2 coupled sea-ice- -ocean model (Timmermann and others, 2002; Assmann and others, 2003). Salinity and temperature are derived from the World Ocean Circulation Experiment (WOCE) dataset (Gouretski and others, 1999). A 6 hour time-step is applied.

More details about the model can be found in section 6 .

\subsection{Choice of model parameter values}

The sea-ice model contains a large number of parameterizations, not all of which can be determined directly by observations. For our study, the application of some commonly assumed parameter values resulted in realistic simulation of the ice cover, while other parameter values had to be adjusted to match field observations. In this subsection, we discuss the rationale behind the choice of a number of parameter values.

Earlier studies have shown that summer ice extent is sensitive to the parameterization of snow and ice albedo (Fischer and Lemke, 1994). Warm temperatures and high solar radiation in summer induce melting and, occasionally, melt ponds, hence melting snow and ice are usually treated with a reduced surface albedo (Parkinson and Washington, 1979). However, in the Ross Sea in summer, extensive melting and flooding of the ice pack are widespread, but bare ice and melt ponds have not been observed (Morris and Jeffries, 2001). Thus, surface albedo remains high, and all-wave albedo measurements range from 0.7 to 0.86 , with a possible increase of an average of $1.4 \%$ and a maximum of $4 \%$ due to clouds (Zhou and others, 2001). Following these observations, we employ values of 0.80 and 0.75 as the albedos of snow and ice under melting conditions and maintain the albedo of frozen snow and ice at 0.85 and 0.75 in the model. This parameterization results in a realistic simulation of the summer ice extent (see section 5).

Sea-ice drift is determined by the sea-ice momentum balance, of which atmospheric and oceanic stresses and internal forces within the ice cover are the most significant terms (Hibler, 1979). The effect of winds and ocean currents on the ice is parameterized using the atmospheric and oceanic drag coefficients, $c_{\mathrm{a}}$ and $c_{\mathrm{w}}$. It is the $c_{\mathrm{a}} / c_{\mathrm{w}}$ ratio, and not the absolute values of $c_{\mathrm{a}}$ and $c_{\mathrm{w}}$, that determines the drift behaviour of the ice (Fischer and Lemke, 1994). Internal forces are parameterized using two ice-strength parameters, $P^{*}$ and $C^{*}$, which determine the degree to which the ice can be compressed. In regions of convergence or shearing, a high ice strength slows down ice drift (Geiger and others, 1998) and reduces the ice thickness while exerting little influence on ice extent (Stössel and others, 1990). In accordance with the findings of the optimization study of Harder and Fischer (1999), we found that the choice of $c_{\mathrm{a}}=1.6 \times 10^{-3}, \quad c_{\mathrm{w}}=4.510^{-3}, \quad P^{*}=20000 \mathrm{~N} \mathrm{~m}^{-2}$ and $C^{*}=20$ provide the best results for simulating sea-ice drift (see section 5).

\section{COMPARISON BETWEEN NUMERICAL SIMULATION AND FIELD OBSERVATIONS OF THE ROSS SEA ICE CONDITIONS IN 1998 AND 1999}

\subsection{Sea-ice extent}

Figure 4 shows the simulated sea-ice extent superimposed on the ice extent measured by the Special Sensor Microwave Imager $(\mathrm{SSM} / \mathrm{I})$. There is close agreement between simulated and observed ice extent in the winter months (e.g. May and September 1998). The seasonal cycles of the simulated and observed ice covers are also in good agreement, reaching maximum ice extent in September and minimum ice extent in February, although the simulated 




Fig. 4. Seasonal evolution of the ice-covered area in the Ross Sea, 1998-99. Shaded areas indicate ice concentrations of $>15 \%$ from SSM/I data. Solid contour lines indicate the ice edge as defined by an ice concentration of $15 \%$ from model simulation.

ice edge is too far north in January. In both simulation and observation, melting begins both at the northern ice edge and at the front of the Ross Ice Shelf in December. However, melting along the Pennell and Oates Coasts is too vigorous in the simulations.

\subsection{Ice thickness}

Ice thickness is simulated for the same time and location as the ASPeCt summary observations given in Figure 1. Simulated ice thickness and the equivalent ice thickness derived from ASPeCt data are plotted in Figure 2.

The simulated equivalent ice thicknesses along $180^{\circ} \mathrm{ex}-$ ceed that of the observed values. However, along $165^{\circ} \mathrm{W}$ and $150^{\circ} \mathrm{W}$, simulated equivalent ice thicknesses either agree with or are less than observed values. In trend, however, along $180^{\circ}$ and $150^{\circ} \mathrm{W}$, both simulated and observed ice thicknesses decrease towards the northern ice edge and towards the continent to the south, while they both show a meridional gradient along $165^{\circ} \mathrm{W}$, with the minimum ice thickness in the north. The model overestimates ice thickness in the region between $66^{\circ} \mathrm{S}$ and $71^{\circ} \mathrm{S}$ along $180^{\circ}$ in the autumn ice cover and underestimates ice thickness in the regions south of $72^{\circ} \mathrm{S}$ along $165^{\circ} \mathrm{W}$ and between $72^{\circ}$ and $73^{\circ} \mathrm{S}$ along $150^{\circ} \mathrm{W}$ in the summer ice cover. In the regions where ice thickness is underestimated, the variation of simulated ice thickness follows the same pattern as the variation of observed areal coverage of ridges, and differs from the pattern of observed sail height. This indicates that the amount of deformation activity is reproduced reasonably well by the model, while the discrepancy between the simulated and observed ice thicknesses is mainly due to deficiencies in quantifying the increase of ice thickness during each deformation event.

\subsection{Sea-ice drift}

Figure 3 plots the simulated and observed trajectories of the buoys deployed during NBP 98-3 and NBP 99-1. The simulated trajectories are derived from the simulated Eulerian ice velocities by setting the start position and date of the simulated trajectories to those of the observed buoys and then successively calculating the movement of a hypothetical ice particle for each time-step. Velocity components are interpolated bilinearly to the simulated buoy position for each time-step. Once the simulated trajectory has significantly drifted away from the observed buoy track, it experiences a different forcing and thus cannot be expected to match the observation accurately (Harder and Fischer, 1999). Therefore, the simulated trajectory is restarted at the location along the observed buoy track after every 60 days.
Figure 3 shows that the model captures the large-scale drift pattern reasonably well. Features like the westward drift along the coastal current, the northward drift out of the Ross Sea and the eastward-flowing ACC are reproduced quite realistically. However, in general, the model has difficulty in capturing variations in the north-south direction. Drift velocities are generally slower than observed, and the model drift is overly eastward in the western Ross Sea.

These discrepancies may arise from insufficiencies in the forcing fields as well as in the physical model. The resolutions of NCEP forcing fields and the model are $2.5^{\circ} \times 2.5^{\circ}$ and approximately $1.5^{\circ} \times 1.5^{\circ}$, respectively. Since the drift tracks of each of the buoys deployed on NBP 99-1 span an area of $<5^{\circ}$ latitude, only two to three forcing-field points in the meridional direction are used for simulating the drift. Local variations on scales smaller than the model grid size or the spatial resolution of the forcing fields naturally are smoothed out and hence are underrepresented in the simulation results. Other studies have shown that NGEP reanalysis underestimates wind speeds by roughly $20 \%$ (Smith and others, 2001). As this may be contributing to the discrepancies between the simulated and observed drift, we tried to simulate ice drift with wind speeds arbitrarily increased by $20 \%$. We found that this resulted in other discrepancies between simulated and observed trajectories and conclude that the underestimation of wind speeds is not the sole cause of the discrepancies between observed and simulated drifts that are illustrated in Figure 3.

\section{USING BACKWARD TRAJEGTORIES TO ANALYZE SEA-ICE HISTORY}

\subsection{Components of ice-thickness evolution}

The evolution of ice and snow thicknesses is governed by partial differential equations for the prognostic variables of bulk ice thickness (ice volume per unit gridcell area), $h$, bulk snow thickness, $h_{\mathrm{sn}}$, ice concentration, $A$, and sea-ice drift speed, $u_{\mathrm{i}}$. The Eulerian rate of change of bulk ice thickness, $\mathrm{D} h / \mathrm{D} t$, comprises the local rate of change, $\partial h / \partial t$, the rate of change due to advection, $u_{\mathrm{i}} \cdot \nabla h$, and the rate of change due to convergent or divergent ice drift, $h \cdot \nabla \vec{u}_{\mathrm{i}}$ :

$$
\frac{\mathrm{D} h}{\mathrm{D} t}=\frac{\partial h}{\partial t}+u_{\mathrm{i}} \cdot \nabla h+h \cdot \nabla \vec{u}_{\mathrm{i}}
$$

(Hibler, 1979). Similar expressions can be written for $h_{\mathrm{sn}}$ and $A$. Local changes in ice thickness and concentration arise from the thermodynamic effects of freezing and melting, $(\partial h / \partial t)_{\text {thermo }}$ and $(\partial A / \partial t)_{\text {thermo }}$, the effect of snow-ice 
formation, $(\partial h / \partial t)_{\text {flood }}$, and the dynamic effects of shear deformation, $(\partial A / \partial t)_{\text {shear }}$ :

$$
\begin{aligned}
\frac{\partial h}{\partial t} & =\left(\frac{\partial h}{\partial t}\right)_{\text {thermo }}+\left(\frac{\partial h}{\partial t}\right)_{\text {flood }} \\
\frac{\partial A}{\partial t} & =\left(\frac{\partial A}{\partial t}\right)_{\text {thermo }}+\left(\frac{\partial A}{\partial t}\right)_{\text {shear }}
\end{aligned}
$$

The freezing and melting rates of sea ice are determined as the residuum of the surface heat budget (Parkinson and Washington, 1979). If the ocean is at the freezing temperature and further atmospheric heat loss cannot be balanced by an upward heat flux in the ocean, the heat budget is closed by the gain of latent heat during sea-ice formation. This directly gives the thermodynamic change in ice thickness, $(\partial h / \partial t)_{\text {thermo }}$. The thermodynamic change of ice concentration $(\partial A / \partial t)_{\text {thermo }}$ is parameterized as a function of $(\partial h / \partial t)_{\text {thermo }}$ (Hibler, 1979). The effect of snow-ice formation is determined from the hydrostatic balance of the snow and ice layers. When the snow/ice interface is submerged below sea level, $(\partial h / \partial t)_{\text {flood }}$ becomes positive as the submerged snow freezes and is converted to snow ice (Leppäranta, 1983). The shear term, $(\partial A / \partial t)_{\text {shear }}$, which is also referred to as the ridging term (Harder and Lemke, 1994), describes a dynamic redistribution of sea ice due to shear deformation. As the ice cover deforms in shear, the open-water area is increased, reducing the ice concentration, $A$, but effecting no change in the ice volume per unit gridcell area, $h$. More dynamic redistribution of sea ice is described by the convergence and divergence term, $h \cdot \nabla \vec{u}_{\mathrm{i}}$, with the tendency for $h$ and $A$ to decrease under divergence and to increase under convergence.

To allow for a consistent diagnosis of all processes related to changes in sea-ice thickness, we focus on the rate of change of ice volume per unit ice-covered area. Ice volume per unit ice-covered area or actual ice thickness, $z_{\mathrm{i}}$, is defined as

$$
z_{\mathrm{i}}=\frac{h}{A}
$$

The rate of change of $z_{\mathrm{i}}$ is related to the rate of change of $h$ and $A$ through Equations (3a) and (3b) via the quotient rule:

$$
\frac{\partial z_{\mathrm{i}}}{\partial t}=\frac{1}{A}\left(\frac{\partial h}{\partial t}-z_{\mathrm{i}} \frac{\partial A}{\partial t}\right)
$$

\subsection{Lagrangian analysis using backward trajectories}

Switching from an Eulerian to a Lagrangian perspective, the effect of advection is removed. Substituting Equations (3a) and (3b) into Equation (5), the rate of change of actual ice thickness for a Lagrangian particle, $\left(\partial z_{i} / \partial t\right)_{\text {Lagrangian }}$, is

$$
\begin{aligned}
\left(\frac{\partial z_{\mathrm{i}}}{\partial t}\right)_{\text {Lagrangian }}= & \left(\frac{\partial z_{\mathrm{i}}}{\partial t}\right)_{\text {thermo }}+\left(\frac{\partial z_{\mathrm{i}}}{\partial t}\right)_{\text {flood }}+\left(\frac{\partial z_{\mathrm{i}}}{\partial t}\right)_{\text {shear }} \\
& +\left(\frac{\partial z_{\mathrm{i}}}{\partial t}\right)_{\text {dyn }},
\end{aligned}
$$

where $\left(\partial z_{\mathrm{i}} \partial t\right)_{\mathrm{dyn}}$ accounts for changes in actual thickness due to the dynamic processes of convergence and divergence. The terms on the righthand side will be analyzed along the trajectory of a Lagrangian particle following the sea-ice velocity field.

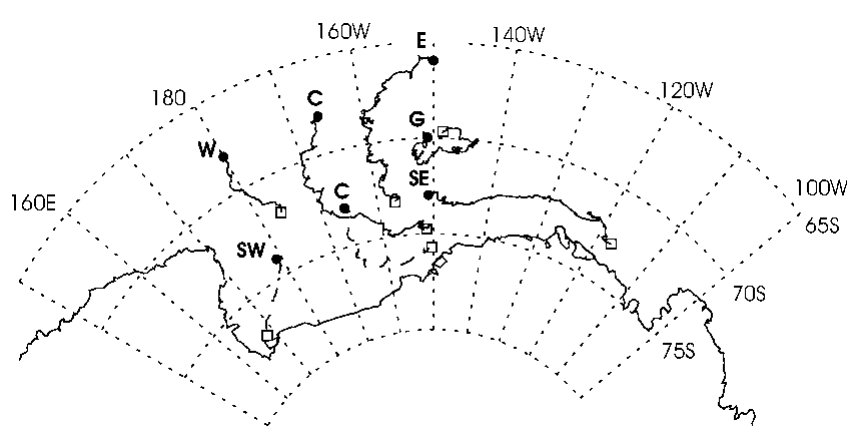

Fig. 5. Examples of the simulated trajectories of ice floes prior to their encounter with cruises $\mathcal{N B P} 98-3$ and NBP 99-1. The groups of trajectories are referred to as Western $(W)$, Southwestern ( $S W)$, Central ( $C$ ), Eastern (E), Gyre $(G)$ and Southeastern (SE). Described forward in time, $\square$ denote the beginning of trajectories, which was 2 months prior to observation in the case of ice along $180^{\circ}$, and 10 months prior to observation in the case of ice along $175^{\circ} \mathrm{W}$ and $150^{\circ} \mathrm{W}$. denote the end of trajectories, i.e. at the location of observation.

Computation of backward trajectories is similar to simulating forward trajectories as described in section 3. Each backward trajectory is initiated at the position of an ASPeCt summary observation (Fig. 1). In order to match up with field observations, backward trajectories were initiated on 15 May 1998 along $180^{\circ}$ and on 15 January 1999 along $175^{\circ} \mathrm{W}$ and $150^{\circ} \mathrm{W}$. The hypothesized ice floe is successively moved in the opposite direction of the velocity vector at the present location to arrive at the location of the previous time-step. All backward trajectories are stopped on 15 March 1998, which is assumed to be the end of the 1997/98 melt season. Simulated buoys are also stopped when they encounter open water. Starting from the earliest date of the backward trajectory, processes are analyzed in a forward integration along the now known trajectory.

\section{RESULTS OF BACKWARD TRAJEGTORY ANALYSIS}

\subsection{Backward trajectories initiated along $180^{\circ}$ on 15 May 1998}

The first set of backward trajectories was initiated at the location of ten summary observations along $180^{\circ}$ on 15 May 1998 (Fig. 1). The resultant floe trajectories (to be described forward in time) fall into two main groups (Fig. 5). Western (W) trajectories originate from the central Ross Sea near $180^{\circ}$, on or just after 15 March 1998, and follow a mean path along $180^{\circ}$ northward. Southwestern (SW) trajectories originate from the southwestern Ross Sea usually between mid-March and mid-April and lead northeastward. Out of the ten floe trajectories, there are six $\mathrm{W}$ and four SW trajectories.

Ice thickness increases along these trajectories, with thermodynamic thickening being the dominant thickening process (Fig. 6a-d). Thermodynamic thickening peaks at the end of March and decreases with time, as the floes thicken as they drift northward (Figs $6 \mathrm{~b}$ and 7). Higher temperatures at more northerly latitudes combine with increasing ice thickness and snow accumulation with time to reduce the vertical temperature gradient across the ice. Thus the 

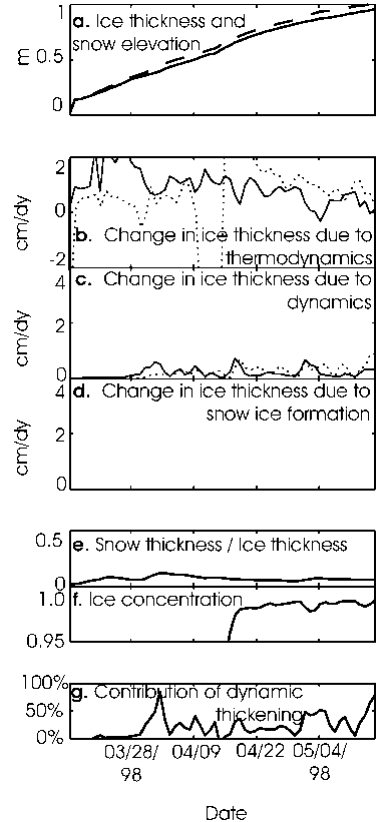

Fig. 6. Simulated characteristics and activity of thickening processes for ice floes that were observed along $180^{\circ}$ in May 1998. In (a) and (e-g), heavy lines indicate mean values across all $W$ and $S W$ trajectories. In $(b-d)$, light solid lines indicate values along $W$ trajectories, and dotted lines indicate values along $S W$ trajectories. The respective plots are of (a) ice thickness (solid line) and snow elevation (dashed line); (b) rate of change of ice thickness due to thermodynamic effects; (c) rate of change of ice thickness due to dynamic effects; (d) rate of change of ice thickness due to snow-ice formation; (e) ratio between snow thickness and ice thickness; $(f)$ ice concentration; and $(g)$ contribution of dynamic thickening to net ice-thickening rates.

conductive heat flux and the net freezing rate are also reduced. Isolated melt events are found along SW trajectories in the region of the Ross Polynya (Figs 6b and 7). Snow-ice formation is negligible along $\mathrm{W}$ and SW

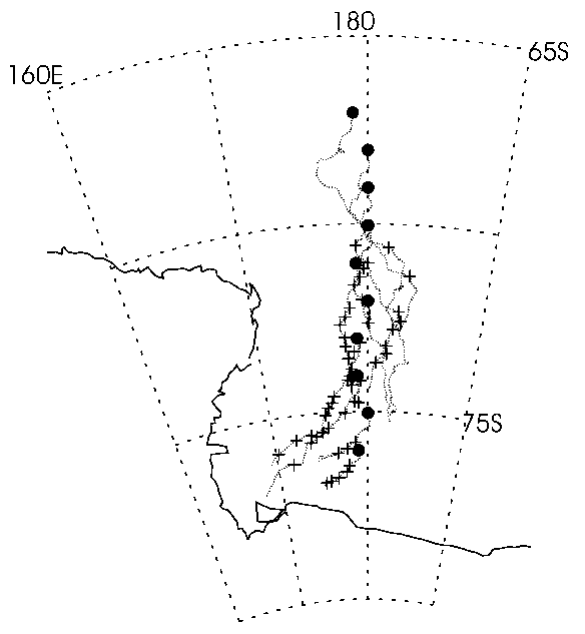

Fig. 7. Locations of high thermodynamic thickening activity along $W$ and $S W$ trajectories. + denote rates of $>1.0 \mathrm{~cm} \mathrm{~d}^{-1}$. - are the locations of the ASPeCt summary observations and are assumed to be the locations of the hypothesized ice floes on 15 May 1998. Lines indicate the paths of trajectories. Trajectories start on 15 March 1998 and end on 15 May 1998.
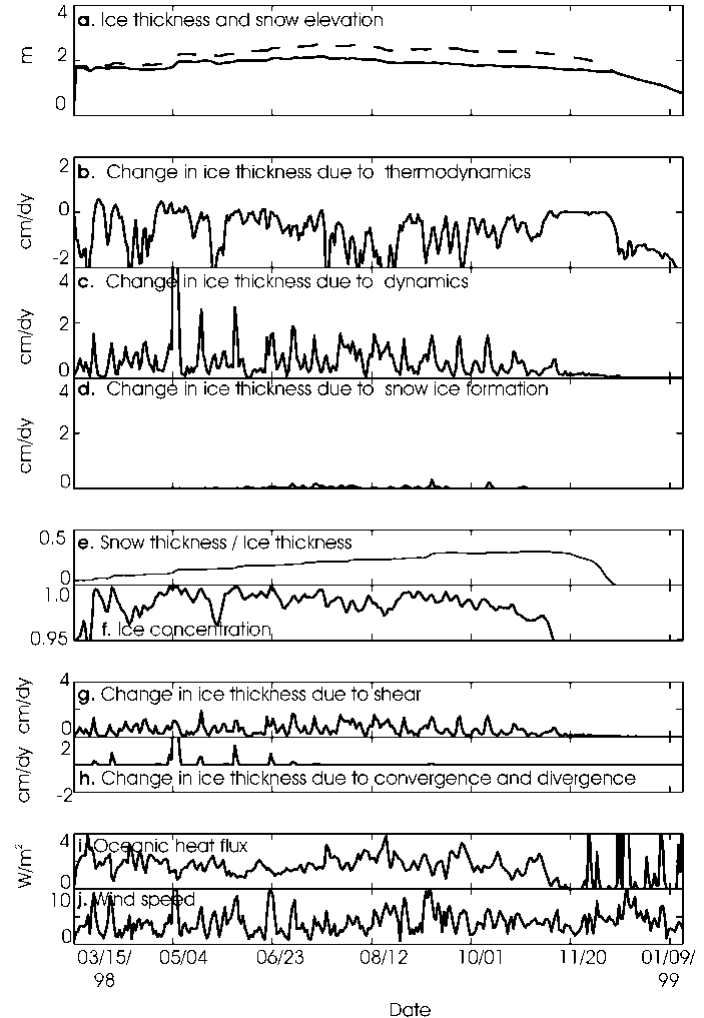

Fig. 8. Simulated characteristics and activity of thickening processes for ice floes that were observed along $180^{\circ}$ in Fanuary 1999. All lines indicate mean values across all $C$ trajectories. The respective plots are of (a) ice thickness (solid line) and snow elevation (dashed line); ( $b$ ) rate of change of ice thickness due to thermodynamic effects; (c) rate of change of ice thickness due to dynamic effects; (d) rate of change of ice thickness due to snow-ice formation; (e) ratio between snow thickness and ice thickness; $(f)$ ice concentration; ( $g$ ) rate of change of ice thickness due to shear deformation; $(h)$ rate of change of ice thickness due to convergence and divergence; (i) oceanic heat flux; and $(j)$ wind speed.

trajectories due to a combination of low snow and high ice thicknesses that leads to a small ratio between snow and ice thickness (Fig. 6a, d and e). Dynamic thickening becomes active after the end of March and contributes a mean of $20 \%$ towards the total thickening rate along the W and SW trajectories (Fig. 6c and g).

\subsection{Backward trajectories initiated along $165^{\circ} \mathrm{W}$ and $150^{\circ}$ W on 15 January 1999}

The second set of backward trajectories was initiated at the location of seven summary observations along $165^{\circ} \mathrm{W}$ on 15 January 1999 (Fig. 1). All floe trajectories originate from the western front of Marie Byrd Land on 15 March 1998. They travel westward into the Ross Sea and turn northward between $165^{\circ} \mathrm{W}$ and $175^{\circ} \mathrm{W}$ (Fig. 5). The northernmost floes join the ACG and turn towards the northeast. Since trajectories differ little except in total displacement, all these trajectories are analyzed together and referred to as Central (C) trajectories.

Backward trajectories were also initiated at the location of nine summary observations along $150^{\circ} \mathrm{W}$ on 15 January 1999 (Fig. 1). These floe trajectories are categorized as Eastern (E), Gyre $(\mathrm{G})$ or Southeastern (SE) trajectories (Fig. 5). 

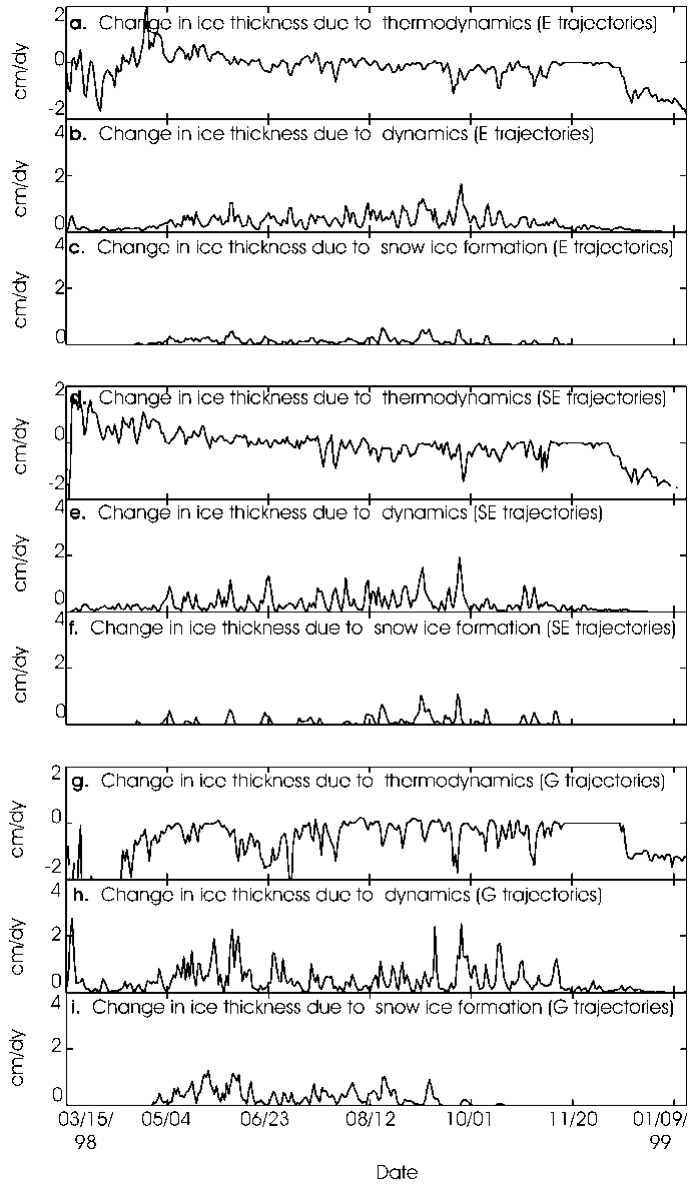

Fig. 9. Simulated characteristics and activity of thickening processes for ice floes that were observed along $150^{\circ} \mathrm{W}$ in January 1999. All lines indicate mean values across all E, $S E$ and $G$ trajectories. The respective plots are of (a) ice thickness (solid line) and snow elevation (dashed line); (b) ratio between snow thickness and ice thickness; (c) ice concentration; (d) rate of change of ice thickness due to shear deformation; (e) rate of change of ice thickness due to convergence and divergence; $(f)$ oceanic heat flux; $(g)$ wind speed; and $(h)$ precipitation rate.

Three E trajectories originate west of $150^{\circ} \mathrm{W}$ and initially travel northwestward until they join the ACC. Five G trajectories originate close to $150^{\circ} \mathrm{W}$ and are trapped in the center of the Ross Gyre, resulting in little overall displacement. The two SE trajectories originate east of $150^{\circ} \mathrm{W}$ and lead westward with the coastal current and the easterly winds.

Ice floes along $\mathrm{C}$ trajectories start at the end of the melt season in March with a thickness of 1.5-2 m (Fig. 8a). This perennial ice thickens slowly between March and June and begins to thin in November. Melting is the dominant thermodynamic process throughout the analyzed period between March and the following January and is balanced by significant dynamic thickening and a small amount of snow-ice formation in the winter months March-October (Fig. 8b-d).

Ice floes along $\mathrm{E}, \mathrm{SE}$ and $\mathrm{G}$ trajectories thicken rapidly between March and October and begin to thin in November (Fig. 9a). Thermodynamic thickening is active along $\mathrm{E}$ and SE trajectories prior to May (Fig. 10a, d and g). Between May and November, significant dynamic thickening and snow-ice formation dominate over melting and result in a

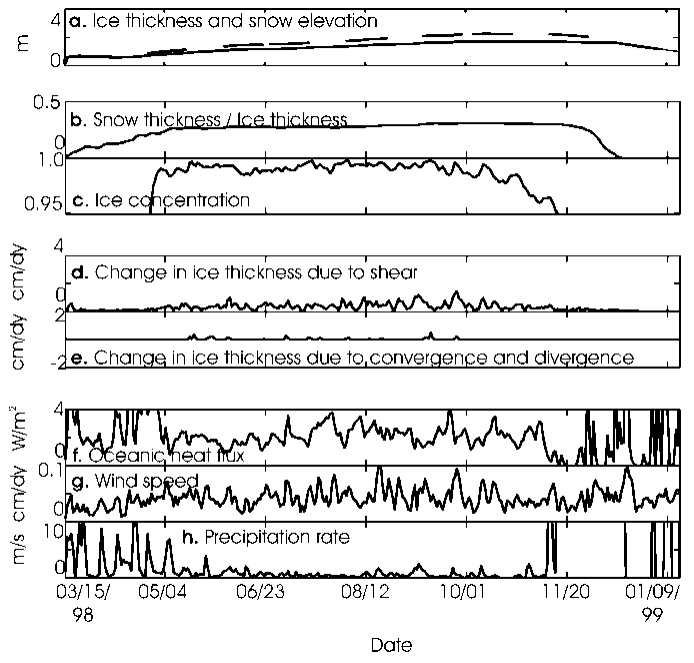

Fig. 10. Simulated activity of thermodynamic and dynamic thickening and snow-ice formation for ice floes that were observed along $150^{\circ} \mathrm{W}$ in fanuary 1999 . The respective plots are of the mean activity along $E(a-c), S E\left(d^{-} f\right)$ and $G$ $(g-i)$ trajectories.

net thickening of the floes along all E, SE and $\mathrm{G}$ trajectories (Figs 9a and 10). However, after November, melting dominates and ice thickness decreases rapidly.

Along C, E, SE and G trajectories, melting takes place during three periods (Figs $8 \mathrm{~b}$ and $10 \mathrm{a}, \mathrm{d}$ and $\mathrm{g}$ ): from 15 March 1998 to the end of April, from the end of May to the end of October, and from the beginning of December 1998 to 15 January 1999. Along $\mathrm{C}$ and $\mathrm{E}$ trajectories, the first and third melt periods coincide with the southern- and northernmost latitudes at the beginning and end of the trajectories (Fig. 11). SE trajectories follow a predominantly zonal path from east to west, hence the first and third melt periods coincide with the eastern- and westernmost positions. The second melt period occurs at different locations along the trajectories. Overall, this points to time rather than location as the primary control over the onset of melt periods. For all C, E, SE and G trajectories, events of high melting activity

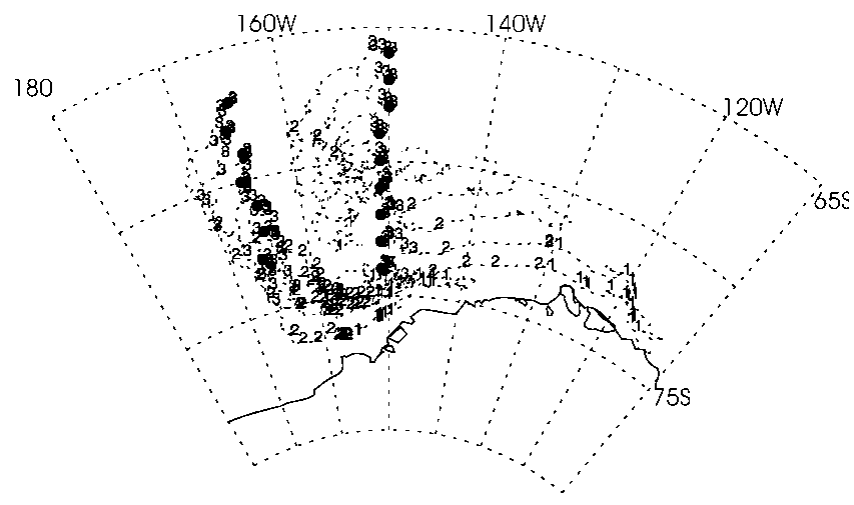

Fig. 11. Locations of high melting activity along $C, E, S E$ and $G$ trajectories. Numbers $1-3$ denote rates of $>1.0 \mathrm{~cm} \mathrm{~d}^{-1}$ during periods (1) 15 March 1998 to 15 June 1998, (2) 16 June 1998 to 15 September 1998, and (3) 16 September 1998 to 15 January 1999. - are the locations of the ASPeCt summary observations and are assumed to be the locations of the hypothesized ice floes on 15 January 1999. Lines indicate the paths of trajectories. Trajectories start on 15 March 1998 and end on 15 January 1999. 
during the second melt period coincide with events of high dynamic thickening activity and high oceanic heat flux (Figs 8-10). The reasons for this coincidence and possible sources of melting are discussed in section 8.1.

High dynamic thickening activity is concentrated along the coast and in the regions where drift direction changes from traveling westward into the Ross Sea to traveling northwards (Fig. 12). For C trajectories, peak dynamic thickening activity is found in the regions south of $75^{\circ} \mathrm{S}$ and west of $160^{\circ} \mathrm{W}$ where field observations have also indicated an abundance of high ridge sails (Figs 4 and 12). Along E, SE and $\mathrm{G}$ trajectories, peak dynamic thickening activity is located in the regions $70^{\circ} \mathrm{S}, 155^{\circ} \mathrm{W} ; 74-78^{\circ} \mathrm{S}, 150-160^{\circ} \mathrm{W}$; and $74^{\circ} \mathrm{S}, 165^{\circ} \mathrm{W}$ (Fig. 12). Along C, E, SE and G trajectories, dynamic thickening activity decreases with time, while the floes drift northward toward the ice edge (Figs $8 \mathrm{c}, 10 \mathrm{~b}$, e and $\mathrm{h}$ and 12). At this stage, stresses in the ice cover are readily dissipated as ice concentration is decreased due to melt (Figs 8f and 9c), and motion is less constrained at the ice edge, resulting in reduced dynamic thickening activity. Shear deformation is found to be the dominant process of dynamic thickening (Figs $8 \mathrm{~g}$ and $\mathrm{h}$ and $9 \mathrm{~d}$ and e). Events of high dynamic thickening due to shear are accompanied by events of high oceanic heat flux and high winds (Figs 8g, i and $\mathrm{j}$ and $9 \mathrm{~d}, \mathrm{f}$ and $\mathrm{g}$ ). The consequences of this coincidence are discussed in section 8.1.

Snow-ice formation is widespread along E, G and SE trajectories (Fig. 10c, f and i). It occurs between the beginning of May and the end of October, which coincides with the period of peak dynamic thickening activity, with events of high snow-ice formation being associated with events of high precipitation and wind speeds (Figs $9 \mathrm{~g}$ and $\mathrm{h}$ and $10 \mathrm{c}$, $\mathrm{f}$ and i). During this peak period, snow accumulates on increasingly thicker ice, maintaining a ratio between snow and ice thickness which is consistently $>0.3$ (Fig. 9b). Prior to and after this period, snow accumulation is found to be insufficient to allow for the formation of snow ice, even during high precipitation events.

\section{DISGUSSION}

\subsection{Evolution of sea-ice thickness in the Ross Sea}

Model results indicate that thermodynamic thickening was the dominant process in determining the thickness of firstyear ice found in the western Ross Sea in May 1998. This is consistent with ice-core data collected during NBP 98-3 that show a majority of congelation ice in the cores (Jeffries and others, 2001). Frazil ice was found to make up one-third of the total ice mass. This supports our finding that, although thermodynamics dominates during this period, dynamic thickening also plays a significant role in the development of ice thickness in autumn.

The remaining $10 \%$ of the ice cores comprised snow ice and was not reproduced by the model. This discrepancy appears to arise from an underestimation of snow thickness and an overestimation of ice thickness along W and SW trajectories. Following the hydrostatic equation, an ice floe will flood if it meets the criterion (Eicken and others, 1994)

$$
\frac{z_{\mathrm{S}}}{z_{\mathrm{i}}}>\frac{\left(\rho_{\mathrm{sw}}-\rho_{\mathrm{i}}\right)}{\rho_{\mathrm{s}}}
$$

where $z_{\mathrm{s}}$ is snow thickness, $z_{\mathrm{i}}$ is ice thickness, $\rho_{\mathrm{S}}$ is snow den-

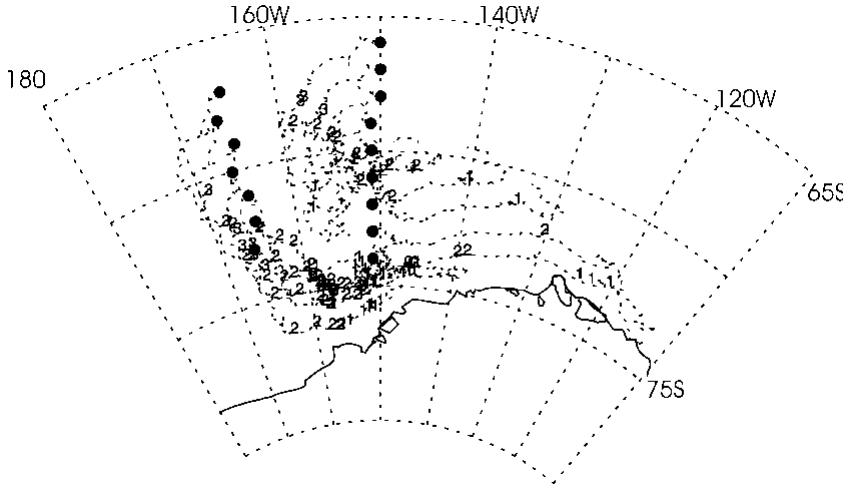

Fig. 12. Same as Figure 11, but for high dynamic thickening activity.

sity, $\rho_{\mathrm{i}}$ is ice density (assumed to be $900 \mathrm{~kg} \mathrm{~m}^{-3}$ ), and $\rho_{\mathrm{sw}}$ is sea-water density (1030 $\mathrm{kg} \mathrm{m}^{-3}$; Eicken and others, 1994). In effect, flooding can only occur if a thick snow cover overlies a thin ice floe. Field measurements taken in this area during this period found a mean snow thickness and density of $0.12 \mathrm{~m}$ (Tin and Jeffries, 2001) and $320 \mathrm{~kg} \mathrm{~m}^{-3}$ (Morris and Jeffries, 2001). With these values, Equation (7) indicates that flooding cannot occur on ice floes that are thicker than $0.35 \mathrm{~m}$. However, the model estimates a mean ice thickness of $1.2 \mathrm{~m}$, and simulated ice thicknesses consistently exceed observed values by $0.05-0.7 \mathrm{~m}$ (Fig. 2a). In addition, snow thickness along the simulated $\mathrm{W}$ and SW trajectories is $0.10 \mathrm{~m}$ below the mean observed value for this area (Fig. $6 a)$. The combination of the two is sufficient to inhibit flooding. As a result, while model results present a realistic balance between the roles of thermodynamic and dynamic thickening, the role of snow-ice formation is underestimated.

Along C, E, SE and G trajectories, melting, snow-ice formation and dynamic thickening due to shear are simultaneously active in winter, during the period between the beginning of May and the end of October. The coincidence between events of high melting and high dynamic thickening due to shear can be explained by their coincidence with events of high oceanic heat flux. During shear deformation of the ice cover, open water is increased while existing floes thicken as the ice is piled up (Flato and Hibler, 1991). Ice forms readily over open water at low air temperatures. As new ice starts to form, brine is released into the ocean, inducing entrainment at the mixed-layer base and deepening the mixed layer. This in turn increases the oceanic heat flux to the bottom of the sea ice and induces melting of the existing ice pack. Due to the relatively small fraction of open water, this leads to a net decrease in ice thickness within the gridcell. This explanation is partially supported by data obtained in the Ross Gyre during a cruise in October 1994. Oceanographic data obtained on this cruise indicated the upwelling of warm water, while ice-core data from the vicinity showed widespread melting at the bottom of the sea ice (Jeffries and others, 1995, 2001).

The coincidence between events of high dynamic thickening activity and snow-ice formation in winter arises from passing cyclones that bring both high winds and precipitation. High winds result in ice deformation, while precipitation causes submergence of the snow/ice interface, resulting in snow-ice formation. During summer, melting significantly reduces the snow thickness and compactness of the 


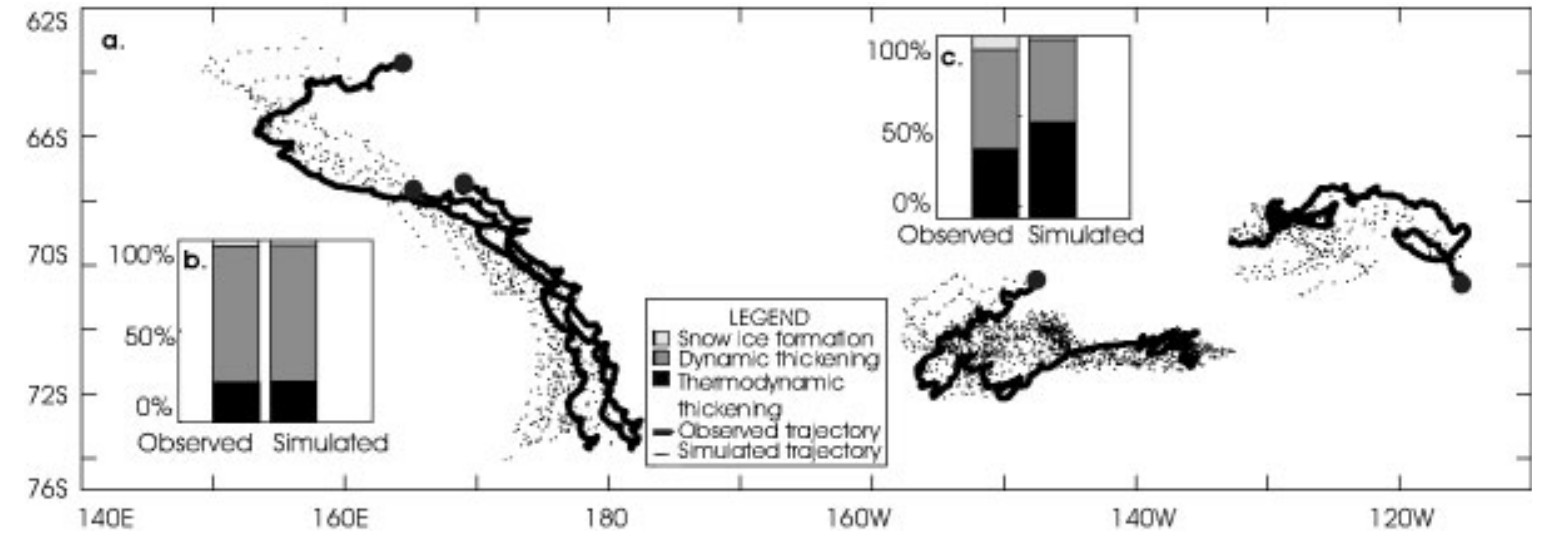

Fig. 13. (a) Observed drift trajectories (solid lines) of buoys deployed during NBP 98-3 and NBP 99-1, and simulated backward trajectories (dots) initiated along the observed trajectories at 10 day intervals. $\bullet$ indicate the locations at which the deployed buoys stopped transmitting. $(b, c)$ Plots of the contributions of different ice-thickening processes to the total thickening rates along observed and simulated trajectories in the western ( $b$ ), and eastern Ross Sea ( $c$ ).

ice pack, inhibiting flooding of the snow/ice interface and build-up of high stresses with the ice pack. As a result, high snow-ice formation and dynamic thickening activities do not occur in summer even during high wind and precipitation events.

\subsection{Errors}

From our comparisons of simulated and observed buoy trajectories of the Ross Sea (section 5), we expect real floes in the western Ross Sea to drift with a stronger westward component near Cape Adare than the simulated W and SW trajectories. Similarly, real floes in the central Ross Sea in 1999 may have encountered larger displacements in the northsouth direction at northern latitudes than the simulated $\mathrm{C}$ and $\mathrm{E}$ trajectories. The parts of the simulated trajectories which are predominantly zonal, such as SE trajectories, are likely to be close to trajectories of real floes, as they are not affected by the coarse resolution of the forcing data in the meridional direction. How does the error in simulating backward trajectories affect our findings on the relative importance of different ice-thickening processes along them? In order to address this question, we initiated backward trajectories at each of the locations and times at which the buoys deployed in NBP 98-3 and NBP 99-1 stopped transmitting. The backward trajectories were then computed back to the times the buoys were deployed. This was repeated along each observed trajectory, with successive backward trajectories being initiated at the location of the deployed buoys 10 days earlier. The rates of thermodynamic and dynamic thickening and snow-ice formation were computed, and their contributions to the total ice-thickening rates were calculated along each trajectory. Figure 13a shows the ensembles of observed and simulated backward trajectories, and Figure 13b and c summarize the relative contributions of the different processes. For the buoys deployed in the western Ross Sea in May 1998, the relative contributions of the different processes along the simulated trajectories do not differ significantly from those along the observed trajectories. However, for the buoys deployed in the eastern Ross Sea in January 1999, model trajectories tend to underestimate the effect of snow-ice formation and dynamic thickening. This is in line with our comparisons of model results with ice-core and ASPeCt data which showed that snow-ice formation in real floes is more active, and that the thickness of deformed ice in the region south of $72^{\circ} \mathrm{S}, 165^{\circ} \mathrm{W}$ is higher than indicated by model results. Figure 12 indicates that errors in the path of simulated trajectories contribute towards this discrepancy.

We conclude that our model results provide a fair overview of the trajectories of ice floes and the relative importance of ice-thickening processes along them, although we expect the contribution of snow-ice formation and dynamic thickening in the Ross Sea to be higher than those reported by our findings.

\section{GONGLUSIONS}

In 1998 and 1999, we collected data on sea-ice thickness, drift and ridging characteristics in the Ross Sea. Mean ice thickness was $0.5 \mathrm{~m}$ in the western Ross Sea in the autumn, and it increased southward from the northern ice edge and northward from the continent until it reached a maximum at $74^{\circ} \mathrm{S}$. A similar pattern in the ice-thickness distribution was found in the eastern Ross Sea in summer. However, the ice was generally thicker, with a mean thickness of $1.4 \mathrm{~m}$ and a maximum of $4.4 \mathrm{~m}$, resulting from a combination of greater areal coverage of ridge sails, higher sail heights and higher level-ice thickness. Sea-ice drift derived from buoys deployed in the western Ross Sea in winter follows a northwest direction around Cape Adare, then continues westward along the Pennell Coast and eventually joins the ACG to turn into an eastward drift. The ice in the eastern Ross Sea was found to drift in two distinct directions. Ice near the coast drifted westward following the coastal current, while ice further north drifted eastward following the ACG towards the Amundsen Sea.

In order to understand the observed ice-thickness distribution we used a regional sea-ice-mixed-layer-pycnocline model to initiate backward trajectories at the time and location of field observations, and examined the dynamic and thermodynamic processes which determine ice thickness along these trajectories. Both our model results and previously published ice-core data indicate that thermodynamic thickening is the dominant process that determines thickness of first-year ice found in the western Ross Sea in the winter. Dynamic thickening also plays a 
significant role and is responsible for $20 \%$ of the net thickening rates. Contrary to ice-core data, model results do not indicate that snow ice forms a significant fraction of mass of this ice. This discrepancy may arise from an underestimation of precipitation and overestimation of ice thickness in the model, and also from errors in the path of simulated trajectories. For the summer ice found in the central and eastern Ross Sea, model results indicate that thermodynamic and dynamic thickening, melting and snow-ice formation all contribute significantly to determine its thickness. Simulations show that thermodynamic thickening is significant only in autumn, while in winter the balance between dynamic thickening, snow-ice formation and basal melting determines whether there is a net thickening or thinning of the ice. Melting dominates in the summer. Model results also reveal the influence that geography exerts over the activity of thickening processes. In regions close to the coast and where ice-drift directions change, high dynamic thickening activity results from the building-up of high internal stress in the ice pack. Lower dynamic thickening activity is found at the northern ice edge where stress can be readily dissipated by northward movement of ice floes. Warmer temperatures at northerly latitudes retard thermodynamic thickening in the winter and reduce snow-ice formation in the summer by inducing melting of the snow cover.

A comparison of model results with field observations indicates that our findings provide a fair overview of the trajectories of ice floes and the relative importance of ice-thickening processes along them, although we expect the contribution of snow-ice formation and dynamic thickening in the Ross Sea to be higher than those reported by our results.

This study has demonstrated that numerical models and detailed field observations can be used together to examine the physical processes underlying observed phenomena in the Antarctic sea-ice pack. Each of these two techniques has its advantages, but no single technique can provide a complete view of the complex ocean-sea-ice-atmosphere system. A combination of techniques can be used in order to amalgamate their advantages. We recommend a stronger coordination between modeling and observing communities, in order to ensure that their works are complementary and support each other's data needs.

\section{ACKNOWLEDGEMENTS}

Thanks to everyone on board the R/V Nathaniel B. Palmer during NBP 98-3 and NBP 99-1 for making fieldwork such an enjoyable experience. Thanks to P. Bond, N. Kozlenko, C. Li, S. Li, T. Maksym, K. Morris, D. Naber, J-L. Tison and $\mathrm{X}$. Zhou for helping to collect the ASPeCt data at all times of the night. Thanks to N. Kozlenko for primary processing of buoy data. This study was funded jointly by U.S. National Science Foundation grant OPP-9614844, a Thesis Completion Fellowship from the Graduate School and by the Geophysical Institute, University of Alaska Fairbanks. A Global Change Student Research Grant from the Center for Global Change and Arctic System Research and a Student Travel Grant from the College of Science, Engineering and Mathematics made T.T.'s visit to Université Catholique de Louvain possible. Sincere thanks to K. Assmann who initiated the collaboration and for providing the model grid and forcing fields. NCEP forcing fields were obtained from the U.S. National Oceanic and Atmospheric Administration-Cooperative Institute for Research in Environmental Sciences (NOAA-CIRES) Climate Diagnostics Center, Boulder, Colorado. Thanks to H. Eicken, K. Echelmeyer and B. Hibler for comments on earlier drafts.

\section{REFERENGES}

Assmann, K., H. H. Hellmer and A. Beckmann. 2003. Seasonal variation in circulation and watermass distribution on the Ross Sea continental shelf. Antarct. Sci., 15(1), 3-11.

Eicken, H., M. A. Lange, H.-W. Hubberten and P.Wadhams. 1994. Characteristics and distribution patterns of snow and meteoric ice in the Weddell Sea and their contribution to the mass balance of sea ice. Ann. Geophysicae, 12(1), 80-93.

Fichefet, Th. and H. Goosse. 1999. A numerical investigation of the spring Ross Sea polynya. Geophys. Res. Lett., 26(8), 1015-1018.

Fischer, H. 1995. Vergleichende Untersuchungen eines optimierten dynamisch-thermodynamischen Meereismodells mit Beobachtungen im Weddellmeer [Comparison of an optimized dynamic-thermodynamic sea ice model with observations in the Weddell Sea]. Ber. Polarforsch. 166. [In German with English summary.]

Fischer, H. and P. Lemke. 1994. On the required accuracy of atmospheric forcing fields for driving dynamic-thermodynamic sea ice models. In Johannessen, O. M., R. D. Muench and J. E. Overland, eds. The polar oceans and their role in shaping the global environment: the Nansen Centennial volume. Washington, DC, American Geophysical Union, 373-381. (Geophysical Monograph 85.)

Flato, G. M. and W. D. Hibler, III. 1991. An initial numerical investigation of the extent of sea-ice ridging. Ann. Glaciol., 15, 31-36.

Geiger, C. A., S. F. Ackley and W. D. Hibler, III. 1998. Sea ice drift and deformation processes in the westernWeddell Sea. In Jeffries, M.O., ed. Antarctic sea ice: physical processes, interactions and variability. Washington, DC, American Geophysical Union, 141-160. (Antarctic Research Series 74.)

Gouretski, V. and 6 others. 1999. Atlas of Ocean Sections. Hamburg, WOCE Hydrographic Programme Special Analysis Centre.

Harder, M. and H. Fischer. 1999. Sea ice dynamics in the Weddell Sea simulated with an optimized model. F. Geophys. Res., 104(C5), 11,151-11,162.

Harder, M. and P. Lemke. 1994. Modelling the extent of sea ice ridging in the Weddell Sea. In Johannessen, O. M., R. D. Muench and J. E. Overland, eds. The polar oceans and their role in shaping the global environment: the Nansen Centennial volume. Washington, DC, American Geophysical Union, 187-197. (Geophysical Monograph 85.)

Hibler, W. D., III. 1979. A dynamic thermodynamic sea ice model. F. Phys. Oceanogr., 9 (7), 815-846.

Jeffries, M. O. and N. Kozlenko. 2002. Buoy deployments in the Ross Sea pack ice, 1998 and 1999. In International programme for Antarctic buoys: report of the third meeting of programme participants. Geneva, World Meteorological Organization. World Climate Research Programme, 11-17. (WCRP Informal Report 5/2002.)

Jeffries, M. O., R. A. Jaña, S. Li and C. McCullars. 1995. Sea-ice and snowthickness distributions in late winter 1993 and 1994 in the Ross, Amundsen and Bellingshausen Seas. Antarct. F. U.S., 30(1-4), 18-21.

Jeffries, M. O., H. R. Krouse, B. Hurst-Cushing and T. Maksym. 2001. Snow-ice accretion and snow-cover depletion on Antarctic first-year sea-ice floes. Ann. Glaciol., 33, 51-60.

Lange, M. A. and H. Eicken. 1991. Textural characteristics of sea ice and the major mechanisms of ice growth in the Weddell Sea. Ann. Glaciol., 15, 210-215.

Lemke, P., W. B. Owens and W. D. Hibler, III. 1990. A coupled sea icemixed layer-pycnocline model for the Weddell Sea. 7. Geophys. Res., 95(C6), 9513-9525.

Leppäranta, M. 1983. A growth model for black ice, snow ice and snow thickness in subarctic basins. Nord. Hydrol., 14(2), 59-70.

Morris, K. and M. O. Jeffries. 2001. Seasonal contrasts in snow-cover characteristics on Ross Sea ice floes. Ann. Glaciol., 33, 61-68.

Owens, W. B. and P. Lemke. 1990. Sensitivity studies with a sea ice-mixed layer-pycnocline model in the Weddell Sea. 7. Geophys. Res., 95(C6), 9527-9538.

Parkinson, C. L. and W. M. Washington. 1979. A large-scale numerical model of sea ice. 7. Geophys. Res., $\mathbf{8 4}(\mathrm{Cl}), 311-337$.

Semtner, A. J., Jr. 1976. A model for the thermodynamic growth of sea ice in numerical investigations of climate. 7. Phys. Oceanogr., 6(5), 379-389.

Smith, S. R., D. M. Legler and K. V. Verzone. 2001. Quantifying uncertainties in NCEP reanalyses using high-quality research vessel observations. 7. Climate, $\mathbf{1 4}(20), 4062-4072$. 
Stössel, A., P. Lemke and W. B. Owens. 1990. Coupled sea ice-mixed layer simulations for the Southern Ocean. 7. Geophys. Res., 95(C6), 9539-9555.

Timmermann, R., P. Lemke and C. Kottmeier. 1999. Formation and maintenance of a polynya in the Weddell Sea. F. Phys. Oceanogr., 29(6), 1251-1264.

Timmermann, R., A. Beckmann and H. H. Hellmer. 2002. Simulations of ice-ocean dynamics in the Weddell Sea. Part 1: Model configuration and validation. 7. Geophys. Res., 107(C3). (10.1029/2000JC00741.)

Tin, T. and M. O. Jeffries. 2001. Sea-ice thickness and roughness in the Ross Sea, Antarctica. Ann. Glaciol., 33, 187-193.

Tin, T. and M. O. Jeffries. 2003. Morphology of deformed first year sea ice features in the Southern Ocean. Cold Reg. Sci. Technol., 36(1-3), 141-163.

Tin, T., M. O. Jeffries, M. Lensu and J. Tuhkuri. 2003. Estimating the thickness of ridged sea ice from ship observations in the Ross Sea, Antarctica. Antarct. Sci., 15(1), 47-54.
Worby, A. and I. Allison. 1999. A technique for making ship-based observations of Antarctic sea-ice thickness and characteristics. Part I: Observational technique and results. Hobart, Tasmania, Antarctic CRC. (Research Report 25.)

Worby, A. P. and X. Wu. 1998. East Antarctic sea ice: observations and modelling. Ann. Glaciol., 27, 427-432.

Zhou, X., S. Li and K. Morris. 2001. Measurement of all-wave and spectral albedos of snow-covered summer sea ice in the Ross Sea, Antarctica. Ann. Glaciol., 33, 267-274.

Zwally, H. J., J. C. Comiso and A. L. Gordon. 1985. Antarctic offshore leads and polynyas and oceanographic effects. In Jacobs, S. S., ed. Oceanology of the Antarctic continental shelf. Washington, DC, American Geophysical Union, 203-226. (Antarctic Research Series 43.)

MS received 24 June 2003 and accepted in revised form 23 January 2004 